\title{
MARKET INTEGRATION - CONCEPTUAL AND APPLICATION ISSUES $₫$
}

\author{
Dr. N S Viswanath * and Dr. S R Narappanavar *
}

\begin{abstract}
Key Words and Phrases : Market Integration, Organically linked markets, "pure error", significant integration, Detrend, Deseasonalise, Decycle, primary and terminal markets.

Correlation is a measure of market integration. Correlation Coefficients of Prices, which include trend, seasonal and cyclical effects are not adequate to precisely measure the degree of market integration. Integration of "pure errors" (pure errors means error series free from autocorrelation effects) of several time series enables us to determine the significance or otherwise integration of markets.
\end{abstract}

\section{Introduction}

Studies in marketing range from pricing; operational and performance efficiencies. These studies are product-commodity oriented and they make efforts to capture efficiency levels in the form of degree of motivation between markets over a time period lagged or otherwise. Further, correlations of new prices are examined over time while selection of a. price variable is a problem in its own right, (in terms of which pricewholesale price, retail price, form price etc.,) the "rawness" of data which include several other "effects" is a matter to examine. The time trend variable is another dimensional issue to count at for correct interpretation

* Principal, M P Birla Institute of Management Associate,

Bharatiya Vidya Bhavan, Bangalore.

* Professor, Department of Studies in Economics, Karnatak University, Dhanwar respectively. @ This paper is based on the Phd Thesis of the first author. 
of results. Some of the studies reviewed suggest that correlation (of prices), as a measure of market integration and hence efficiency, is not an adequate measure because of several reasons. First a new price concedes in itself, trend, reasonability and cycles. Secondly, temporal prices between several markets contain the component of autocorrelation. Thirdly, along with prices, interrelated spatial demand and supply factors, market practices and regulatory measures may influence the levels of integration or otherwise. Fourthly, we expect integration between organically linked markets (in terms of physical products) irrespective of whether they are strong or weak. The real issue is to get at a measure which reflects real state of integration and hence efficiency.

\section{The Conceptual Framework}

The higher the degree of correlation, the higher is the integration. Since higher correlation is relative in its sense it is essential to develop a new concept. Given any two temporal data sets of prices of a product, it is vital to detrend, deseasonalise and decycle the series. This would give us series of error, which are not free from autocorrelation. Develop a lagged autocorrelated model and test it on the series to deautocorrelate. Then the series is left with "pure errors". Correlate these "pure error" series to get at the degree of integration. Test the significance or otherwise of correlation of "pure errors". The significance or otherwise of "p" gives an assessment of market integration. A low value of " $r$ " may be significant. This is a measure different from the one used by Delgado (wherein two way ANOVA is used), as well as Gupta and Muller approach based on Granger causality test and price information base.

\section{Method}

The time series of prices for a product "c" is a function of time. That is

$$
\mathrm{Pt}=\mathrm{F}(\mathrm{t})
$$

Since for a product base the series have to be tested for their degree of association equation 1 becomes

$$
\text { Pct } I=\text { fc }(\mathrm{ti}) \ldots \ldots \ldots(2) \text { wherein } I=1,2, \ldots n \text { for } n \text { markets. }
$$

The equation 2 is assumed to be a multiplicative model, that is,

$$
\text { Pcti }=\text { Tcti } \times \text { Ccti } \times \text { Scti } \times \text { Icti }
$$

Detrend, Deseasonnalise and Decycle the series in equation 3 , then equation 3 becomes

$$
P^{*} \mathrm{cti}=I^{*} \mathrm{cti}
$$


Test equation 4 for the

$R 2 m$ or R2. The Del. The appropriateness of relation by fitting in an otherwise of auto W statistic would enable the model is reflected by the order of the autrelation. The order of us to get at the presence or

$$
I^{*} c t i=a+\left.b\right|^{*} c t i-k+e c t i
$$

Wherein $k$ is the appropriate time lag. random walks across markets for a colation effects) gives the degree of

\section{Interpretation}

Whenever

significance correlation

its logic should ind the markets are significant at "L\%" level of Otherwise, the conceptuat the markets are ontly integrated. This in correlation coefficient mual scepticism would arise organically integrated. markets.

\section{Application}

This concept conventional, coms tested for a cor Five markets, of which thrial and economic impdity marketing system of Comparable varieties three are primary and twance. That is "arecanut". - three each - have of the product in the two terminal, were selected. fifteen in number, is been considered for the al and primary markets level indicating the presen found to be statistically highly significant at $1 \%$ analysis has revealed that 87 out of 105 of first order. The correlation Further penetration revealed the $10 \%$ and $1 \%$ levels coefficients are coefficients are statistically that, as many as $65,10,6,4$ of significance. jevels of significance respectignificant at $0.1 \%, 1 \%, 2 \%, 10 \%$ and 2 correlation within the marketing system. The This reveals presence, $10 \%$ and $5 \%$ whe arecanut markets are subsystems 


\section{References}

1. Blyn, George: Price Series as a Measure of Market Integration: Indian Journal of Agricultural Economics, Vol 28, No2, 1073, pp 56-59.

2. Harris B: There is method in my madness: or is it Vice Versa? Measuring Agricultural Market Performance; Ford Research Institute Studies. Vol 17, pp 197-218.

3. Jayaraj D: Spatial Pricing Efficiency in Groundnut Markets in Tamil Nadu; Indian Journal of Agricultural Economics, Vol 47, No1, Jan-Mar 1992, pp 79-89.

4. Ravallion M: Testing Marketing Integration 'American Journal of Agricultural Economics. Vol 68, No 1, Feb 1986, pp 102-109.

5. Subba Rao K: Rice Marketing System and Compulsory Levies in Andhra Pradesh - A Study of Public intervention in Marketing: Allied Publishers Pvt Ltd, 1978. pp 1 to $173+$ XVI.

6. Delgado C L: A Variance Component Approach to Food Grain Market Integration in Northern Nigeria; American Journal of Agricultural Economics; Vol 68, No 4, Nov 1986, pp 970-979.

7. Gupta S and R A E Mueller: Analyzing the Pricing Efficiency in Spatial Markets. Concepts and Applications; European Review of Agricultural Economics; Vol 9, No 2, 1982, pp 301-312.

8. Gupta S and R A E Mueller: Intertemporal Pricing Efficiency in Agricultural Markets - The case of Slaughter Hogs in West Germany; European Review of Agricultural Economics Vol 0, No 1, 1982, pp 25-29. 